\title{
Efficiency of cloud condensation nuclei formation from ultrafine particles
}

\author{
J. R. Pierce ${ }^{1}$ and P. J. Adams ${ }^{2,3}$ \\ ${ }^{1}$ Department of Chemical Engineering, Carnegie Mellon University, Pittsburgh, PA, USA \\ ${ }^{2}$ Department of Civil and Environmental Engineering, Carnegie Mellon University, Pittsburgh, PA, USA \\ ${ }^{3}$ Department of Engineering and Public Policy, Carnegie Mellon University, Pittsburgh, PA, USA \\ Received: 4 October 2006 - Published in Atmos. Chem. Phys. Discuss.: 3 November 2006 \\ Revised: 26 January 2007 - Accepted: 25 February 2007 - Published: 27 February 2007
}

\begin{abstract}
Atmospheric cloud condensation nuclei (CCN) concentrations are a key uncertainty in the assessment of the effect of anthropogenic aerosol on clouds and climate. The ability of new ultrafine particles to grow to become CCN varies throughout the atmosphere and must be understood in order to understand $\mathrm{CCN}$ formation. We have developed the Probability of Ultrafine particle Growth (PUG) model to answer questions regarding which growth and sink mechanisms control this growth, how the growth varies between different parts of the atmosphere and how uncertainties with respect to the magnitude and size distribution of ultrafine emissions translates into uncertainty in $\mathrm{CCN}$ generation. The inputs to the PUG model are the concentrations of condensable gases, the size distribution of ambient aerosol, particle deposition timescales and physical properties of the particles and condensable gases. It was found in most cases that condensation is the dominant growth mechanism and coagulation with larger particles is the dominant sink mechanism for ultrafine particles. In this work we found that the probability of a new ultrafine particle generating a $\mathrm{CCN}$ varies from $<0.1 \%$ to $\sim 90 \%$ in different parts of the atmosphere, though in the boundary layer a large fraction of ultrafine particles have a probability between $1 \%$ and $40 \%$. Some regions, such as the tropical free troposphere, are areas with high probabilities; however, variability within regions makes it difficult to predict which regions of the atmosphere are most efficient for generating $\mathrm{CCN}$ from ultrafine particles. For a given mass of primary ultrafine aerosol, an uncertainty of a factor of two in the modal diameter can lead to an uncertainty in the number of CCN generated as high as a factor for eight. It was found that no single moment of the primary aerosol size distribution, such as total mass or number, is a robust predictor of the
\end{abstract}

Correspondence to: J. R. Pierce

(jrpierce@andrew.cmu.edu) number of CCN ultimately generated. Therefore, a complete description of the emissions size distribution is generally required for global aerosol microphysics models.

\section{Introduction}

Atmospheric particles influence the radiative balance of the earth's atmosphere by affecting the radiative properties of clouds (commonly referred to as the "indirect effect") because cloud droplets form on a subset of atmospheric particles known as cloud condensation nuclei (CCN) (Albrecht, 1989; Twomey, 1977, 1974). The uncertainty in the magnitude of the indirect effect is the largest contributor to the uncertainty in the overall radiative forcing change since preindustrial times. This uncertainty prevents accurate assessments of the climate sensitivity due to radiative forcing (Andreae et al., 2005; Menon, 2004; Schwartz, 2004). One of the leading causes of uncertainty in the aerosol indirect effect is uncertainty in the $\mathrm{CCN}$ budget (i.e. the concentration of CCN along with its sources and sinks).

The ability of a particle to act as a $\mathrm{CCN}$ is determined by the supersaturation of water vapor along with the size and chemical composition of the particle and is well described by Köhler theory (Seinfeld and Pandis, 1998; Sotiropoulou, et al., 2006). For soluble particles, the activation diameter at $0.2 \%$ supersaturation (representative of stratiform clouds) is approximately $75-120 \mathrm{~nm}$. To first order, low and mid-level stratus clouds have the largest potential for changes in the radiative balance of the earth because they cover much larger areas than convective clouds and are, in general, not as optically thick as convective clouds, which allows for a greater change in albedo for a given $\mathrm{CCN}$ concentration increase

Published by Copernicus GmbH on behalf of the European Geosciences Union. 


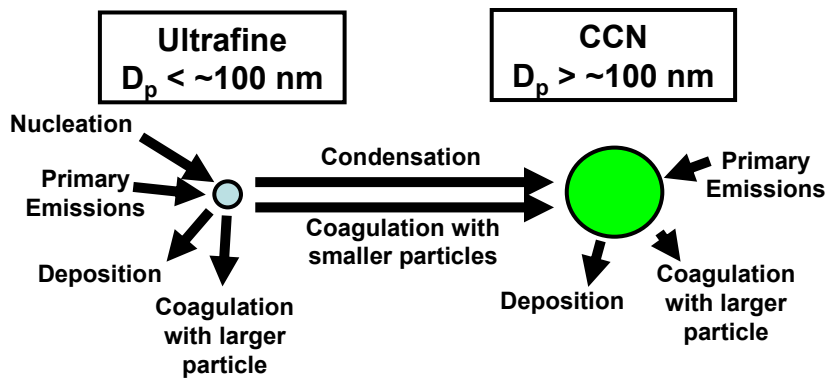

Fig. 1. Source, sink, and growth processes affecting ultrafine and CCN particles.

(Charlson et al., 1992). Therefore, in order for a particle to act as a $\mathrm{CCN}$, its diameter should be as large as $\sim 100 \mathrm{~nm}$.

The two main sources of aerosol number to the atmosphere are nucleation and primary emissions (Putaud et al., 2004; Stanier et al., 2004). Because nucleated particles start in the atmosphere as tiny molecular clusters, they must undergo substantial growth to have an impact atmospheric on CCN concentrations. Kerminen et al. (2004) performed a comparison of growth and sink timescales to determine the ability for fresh nuclei to grow to Aitken mode sized particles; however, the growth from Aitken mode particles to CCN particles was not assessed. Primary emissions of ultrafine particles generally come from combustion sources (Bond et al., 2004; Janhall et al., 2004; Rissler et al., 2006; Zhang et al., 2005) but also have some natural sources such as ultrafine sea-salt (Clarke et al., 2006; O’Dowd et al., 1997; Pierce and Adams, 2006). The sizes of particles emitted from combustion sources depend greatly on the emissions source type, but in general, most of these particles are ultrafine $(<100 \mathrm{~nm})$, so they must also grow to affect CCN concentrations (Janhall et al., 2004; Rissler et al., 2006; Zhang et al., 2005).

With a large fraction of new particles added to the atmosphere being too small to act as CCN immediately, it is important to determine their ability to grow to $\mathrm{CCN}$ size in various parts of the atmosphere. In order to do this, the processes by which particles grow and processes that reduce aerosol number concentrations must be evaluated. As illustrated in Fig. 1, processes that cause ultrafine particles to grow to $\mathrm{CCN}$ sizes are condensation of gases and coagulation while processes responsible for reducing aerosol number concentrations are coagulation and deposition. A large portion of the uncertainty in the $\mathrm{CCN}$ budget stems from largely unconstrained estimates of how new ultrafine particles (defined here as particles smaller than a critical $\mathrm{CCN}$ diameter) grow to sizes where they act as $\mathrm{CCN}$.

The likelihood that an ultrafine particle will grow to $\mathrm{CCN}$ size depends on the competition between the rates of growth and removal processes. The rates of these processes are size and location dependent. Because different sources of ultrafine particles (e.g. nucleation and primary emission) occur in different parts of the troposphere, some may be more ef- fective than others at generating $\mathrm{CCN}$ if they occur where conditions are favorable. For example, areas with high concentrations of condensable gases and low concentrations of existing CCN sizes particles would maximize the formation of CCN from ultrafine particles.

A number of global modeling studies have examined the effect of ultrafine particles on CCN concentrations. Adams and Seinfeld (2003) and Spracklen et al. (2005b) looked at the effect of emitting a small amount of the sulfur emissions as primary sulfate in global models with online size-resolved microphysics of sulfate and sea-salt aerosol. They determined that the ultrafine primary sulfate increases the $\mathrm{CCN}$ concentrations much more efficiently than if the sulfur was emitted as sulfur dioxide gas. Stier et al. (2006) conducted a similar experiment in a global model with online sizeresolved microphysics of sulfate, sea-salt, carbonaceous and dust aerosol. Contrary to the earlier studies, they found that the effect of emitting primary sulfate particles rather than sulfur dioxide was negligible. The difference in results was attributed to the inclusion of the carbonaceous and dust aerosol in Stier et al. (2006); however difference in the assumed size distribution between the studies may also contribute to the differences. The size distribution of primary sulfate used in that work was larger, emitting fewer particles per mass of emissions, but at sizes closer to the $\mathrm{CCN}$ activation diameter. Pierce and Adams (2006) explored the ability of ultrafine sea-salt to contribute to $\mathrm{CCN}$ concentrations estimating that nearly half of $\mathrm{CCN}$ in the southern high latitudes may result from ultrafine sea-salt that grew to $\mathrm{CCN}$ sizes.

The size distributions of primary emissions to the atmosphere are poorly constrained. Due to the regulatory emphasis on particulate mass concentrations, emissions of new particles are often described only by their total mass while their size distributions are undescribed or unmeasured. Global aerosol models used for predicting particle and CCN number concentrations have had to assume size distributions for emissions of primary sulfate and carbonaceous aerosol, thereby adding uncertainty to their predicted $\mathrm{CCN}$ budgets. Moreover, the impact of these assumptions is difficult to evaluate because larger particles grow more easily to $\mathrm{CCN}$ (Adams and Seinfeld, 2002; Spracklen et al., 2005a; Stier et al., 2006). We wish to quantify the uncertainty that results from assuming a size distribution for a given mass of emissions. More generally, we wish to investigate whether a single moment of the aerosol size distribution (e.g. total number or surface area) might be a robust predictor of eventual $\mathrm{CCN}$ formation.

This paper describes the development, testing and application of the Probability of Ultrafine particle Growth (PUG) model that predicts the $\mathrm{CCN}$ formation efficiency from ultrafine aerosol as a function of ultrafine particle size, growth rate, and loss rate. This model was developed to be used as a stand alone model for quick calculations of the $\mathrm{CCN}$ formation efficiencies for a given set of atmospheric conditions. Several applications are illustrated here. First, 
$\mathrm{CCN}$ formation efficiencies are calculated across a range of tropospheric conditions. Second, the rates of the various growth and loss processes (Fig. 1) are compared to determine whether any are dominant. Third, we use the PUG model to assess the uncertainty in eventual $\mathrm{CCN}$ formation from a given primary aerosol mass emission due to the uncertainty in the primary aerosol size distribution. Finally, we ask what parameters of the primary aerosol distribution (e.g. surface area, total number, or complete size distribution) need to be measured to reduce this uncertainty.

The following section discusses the timescales of the various processes of ultrafine particle growth and removal. Section 3 describes the newly developed Probability of Ultrafine particle Growth (PUG) model. Section 4 evaluates the PUG model against a box model with complete aerosol microphysics. Various applications of the PUG model and their results are discussed in Sect. 5, and conclusions are given in Sect. 6.

\section{Ultrafine growth and sink processes}

The first pathway for ultrafine growth is condensation of lowvolatility gases onto the particle including $\mathrm{H}_{2} \mathrm{SO}_{4}, \mathrm{HNO}_{3}$, $\mathrm{NH}_{3}$, and low-volatility organic gases. The increase of a particle's mass from a condensing species is given by (Seinfeld and Pandis, 1998):

$\frac{d m}{d t}=\frac{2 \pi D_{p} D_{i} M_{i}}{R T} f(K n, \alpha)\left(p_{i}-p_{e q}\right)$

In this equation, $m$ is the particle mass, $t$ is time, $D_{p}$ is the particle diameter, $D_{i}$ is the diffusion coefficient of the condensing gas in air, $M_{i}$ is the molecular weight of the condensing gas, $R$ is the gas constant, $T$ is temperature, $f$ is a correction factor for non-continuum effects, $K n$ is the Knudsen number, $\alpha$ is the accommodation coefficient of the condensing gas on the particle, $p_{i}$ is the partial pressure of the condensing gas and $p_{e q}$ is its equilibrium vapor pressure at the particle's surface. This mechanism of growth is most effective when the production rate of low-volatility gases (e.g. oxidation of $\mathrm{SO}_{2}$ or organics) is high and the total surface area of particles is low.

The second process that contributes to the growth of ultrafine particles is coagulation. When two particles coagulate, a single particle is formed with the mass of the two combined particles; therefore, coagulation is both a growth and a loss process. For book-keeping purposes, we define that during a coagulation event, the smaller particle is removed and the larger particle survives and grows by the mass of the smaller particle. The growth rate of a particle with respect to coagulation is then a function of the rate of coagulation with particles smaller than it and the mass of those smaller particles. The increase in mass of a particle of size $D_{p 0}$ by coagulation with smaller particles is given in Eq. (2).

$$
\frac{d m}{d t}=\frac{\pi}{6} \int_{0}^{D_{p 0}} K\left(D_{p 0}, D_{p}\right) N\left(D_{p}\right) \rho\left(D_{p}\right) D_{p}^{3} d D_{p}
$$

In this equation, $D_{p}$ is the diameter of the smaller particles, $K$ is the coagulation kernel, $N$ is the aerosol number size distribution, and $\rho$ is the particle density. This growth pathway is favorable when there are a large number of ultrafine particles.

A potential third growth mechanism for ultrafine particles is by cloud processing including aqueous oxidation of $\mathrm{SO}_{2}$ and cloud droplet collection. Cloud processing can allow a particle with a high initial critical supersaturation to activate at a lower supersaturation in a subsequent cloud cycle (Feingold and Kreidenweis, 2000). By definition, a particle undergoing cloud processing has already acted as a $\mathrm{CCN}$ once. Therefore, we neglect this mechanism here because we are concerned with growth to the first activation event.

There are two major sink pathways for ultrafine particles. The first is coagulation with larger particles, or "coagulational scavenging". The loss rate of a particle of dry diameter $D_{p 0}$ due to coagulation with larger particles may be found through Eq. (3):

$k_{\mathrm{csnk}}=\tau_{\mathrm{csnk}}^{-1}=\int_{D_{p 0}}^{\infty} K\left(D_{p 0}, D_{p}\right) N\left(D_{p}\right) d D_{p}$

In this equation, $k_{\mathrm{csnk}}$ is the effective first-order removal rate constant of particles with diameter $D_{p 0}$ due to coagulation with larger particles, and $\tau_{\text {csnk }}$ is the timescale for this process. This removal mechanism is fast when there are a large number of accumulation and coarse mode particles.

The second sink mechanism for ultrafine particles is deposition, including dry deposition, below-cloud and in-cloud scavenging by rain, and by cloud activation and subsequent precipitation. The rates of these processes depend greatly on the size of the particle, its location in the atmosphere, and meteorology (Seinfeld and Pandis, 1998).

\section{The Probability of Ultrafine particle Growth (PUG) model}

Here we describe the Probability of Ultrafine particle Growth (PUG) model, which calculates the probability that an aerosol of a given initial diameter will grow to a specified $\mathrm{CCN}$ cutoff diameter. The inputs to the model are a preexisting aerosol size distribution, the concentration of condensable gases, size-dependent deposition rates, aerosol and gas physical properties, relative humidity, temperature, and pressure. The pre-existing aerosol size distribution is held constant and is required to calculate the coagulation growth 


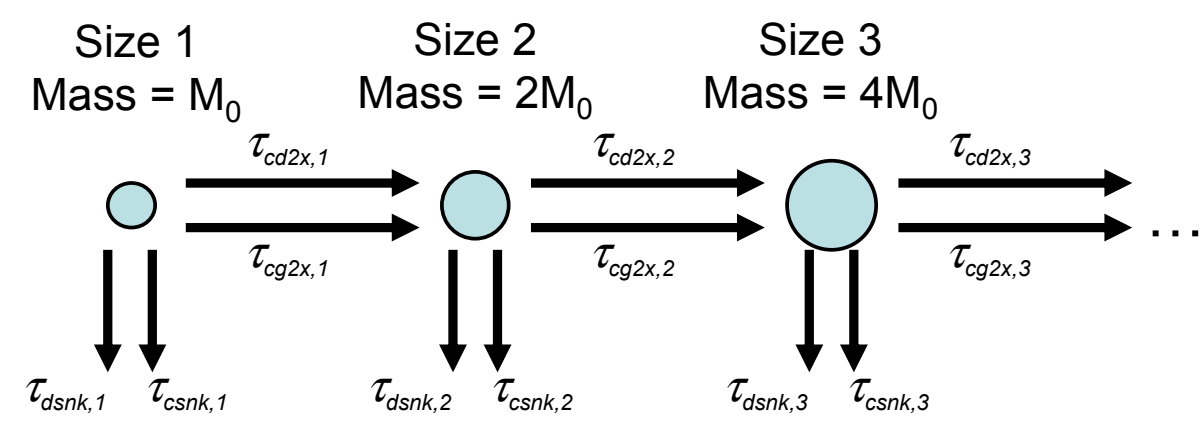

Fig. 2. Overview of size discretization, growth processes, and loss processes in the PUG model. The timescale subscripts, cd2x, cg2x, dsnk and csnk stand for condensational doubling, coagulational doubling, deposition sink and coagulation sink, respectively.

and sink rates. An important assumption inherent in the PUG model is that it calculates the $\mathrm{CCN}$ formation efficiency from ultrafine particles while holding inputs constant. In reality, the addition of new ultrafine particles changes the aerosol size distribution and condensable vapor concentration. These feedbacks are not accounted for in the model; however, in the limit of small amounts of new aerosol, this is negligible.

\subsection{Probability of growth to larger sizes}

Figure 2 describes the structure of the PUG model. Because growth and sink processes are size-dependent, the model calculates the probability of aerosol growth through small discrete steps in which the rates of the growth and sink processes may be considered constant. The growth step sizes are defined by a doubling of dry mass. The distribution of background aerosol is also broken up into discrete size sections defined by dry mass doubling to simplify the coagulation calculations. Probability of aerosol growth between two sizes is defined here as the fraction of ultrafine particles that will grow from the smaller size to the larger size before they are removed. The probability of growth to the next size category is determined by calculating the fraction of particles left after coagulational removal and deposition during the time that it takes the particles to double in mass through condensation and coagulational growth:

$$
P r_{k, k+1}=\exp \left(-\frac{\tau_{2 \mathrm{x}}}{\tau_{\mathrm{snk}}}\right)=\exp \left(-\frac{\left(\tau_{\mathrm{cd} 2 \mathrm{x}, k}^{-1}+\tau_{\mathrm{cg} 2 \mathrm{x}, k}^{-1}\right)^{-1}}{\left(\tau_{\mathrm{csnk}, k}^{-1}+\tau_{\mathrm{dsnk}, k}^{-1}\right)^{-1}}\right)
$$

In this equation, $P r_{k, k+1}$ is the probability that the particle will grow to double its mass (i.e. grow from size section $k$ to $k+1), \tau_{\mathrm{cd} 2 \mathrm{x}, k}$ is the time it would take the particle to double its mass through condensation alone, $\tau_{\mathrm{cg} 2 \mathrm{x}, k}$ is the time it would take the particle to double its mass through coagulation with smaller particles, $\tau_{\mathrm{dnnk}, k}$ is the effective first-order loss timescale of the particle due to deposition and $\tau_{\mathrm{csnk}, k}$ is the first-order loss timescale of the particle due to coagulation with larger particles (first-order because the number of larger particles is held constant). The time it takes for the particle to double its mass due to both growth processes $\left(\tau_{2 \mathrm{x}}\right)$ acting simultaneously is approximated by summing the doubling rates in the numerator of the exponent. The denominator of the exponential is the overall loss timescale, $\tau_{\text {snk }}$, which combines the effects of both coagulation and deposition.

The probability of growth across several size sections (from section $m$ to $n$ ) is calculated as the product of the probabilities of growth through each size section:

$\operatorname{Pr}_{m, n}=\prod_{k=m}^{n-1} P r_{k, k+1}$

Equations (1) through (3) in the previous section may be used to determine timescales for condensational doubling, coagulational doubling and coagulational scavenging. To calculate the timescale to grow from one size section to the next, Eqs. (1) and (2) are simplified by using a constant value of the diameter (represented by subscript $k+$ ) equal to 1.5 times the initial mass during the mass doubling growth. This agrees well with the results of a more accurate differential equation solver. The resulting condensational mass doubling timescale is shown by the following equation.

$$
\begin{aligned}
\tau_{\mathrm{cd} 2 \mathrm{x}, k} & =\frac{m_{k}}{(d m / d t)_{k+}} \\
& =\frac{m_{k} R T}{2 \pi D_{p, k+} D_{i} M_{i} f\left(K n_{k+}, \alpha\right)\left(p_{i}-p_{e q}\right)}
\end{aligned}
$$

In this equation, $m_{k}$ is both the initial dry mass of the particle and the additional mass required to double its dry mass, $D_{p, k+}$ is the constant wet diameter of the particle, and $K n_{k+}$ is the Knudsen number of the wet particle.

The timescale for mass doubling by coagulation with smaller particles is given by:

$$
\tau_{\mathrm{cg} 2 \mathrm{x}, k}=\frac{1}{\sum_{j=1}^{k-1} 2^{j-k} K\left(D_{p, k+}, D_{p, j}\right) N_{j}+\frac{1}{2} K\left(D_{p, k+}, D_{p, k}\right) N_{k}}
$$

In this equation, $N_{j}$ is the number of particles per unit volume in the $j$ th size bin. The first term in the denominator represents coagulation events with the smaller size sections. 
The factor of $2^{j-k}$ represents the mass of the smaller size sections each being a factor of 2 smaller than the previous. The second term in the denominator represents coagulation events with particles in the same size section. The factor of $1 / 2$ accounts for the removal of one of the two same-sized particles from the particle budget.

The equation for the first-order particle loss timescale due to coagulation with larger particles in mass doubling sectional form is shown in Eq. (8).

$$
\tau_{\mathrm{csnk}, k}=\frac{1}{\frac{1}{2} K\left(D_{p, k+}, D_{p, k}\right) N_{k}+\sum_{j=k+1}^{k_{\max }} K\left(D_{p, k+}, D_{p, j}\right) N_{j}}
$$

In Eq. (8), $k_{\max }$ represents the largest size section in the model. The first term in the denominator represents coagulation with particles in the same size section. The second term accounts for coagulation with particles in larger size sections. Deposition removal timescales must be specified for each size range as no meteorology is calculated by the model.

\section{2 $\mathrm{CCN}$ formation efficiency from ultrafine particles}

Consider a steady flux of new ultrafine particles of a certain size being added to an existing size distribution. These new particles will grow through condensation and coagulation to create a new steady-state $\mathrm{CCN}$ concentration, larger than the previous value. The increased $\mathrm{CCN}$ concentration, $\triangle \mathrm{CCN}$, may be expressed as a function of ultrafine-to- $\mathrm{CCN}$ growth probability, $P r_{U F, \mathrm{CCN}}$; the $\mathrm{CCN}$ number lifetime, $\tau_{\mathrm{CCN}}$; and the emissions rate of ultrafines, $\Delta S$ :

$\Delta \mathrm{CCN}=\operatorname{Pr}_{U F, \mathrm{CCN}} \tau_{\mathrm{CCN}} \Delta S$

The number lifetime, $\tau_{\mathrm{CCN}}$, includes both coagulation and deposition as sink processes. It is convenient to re-express $\triangle \mathrm{CCN}$ in terms of the $\mathrm{CCN}$ deposition lifetime, which typically will be nearly equal to the aerosol mass lifetime computed by global models. This happens because most aerosol mass is in particles of CCN sizes, and the removal rate of these particles is dominated by their wet deposition removal rate, which does not vary much with the size of $\mathrm{CCN}$ particles. To do this, note that the probability that a particle that grows to CCN size will be removed by deposition rather than be removed by coagulation is:

$$
\operatorname{Pr}_{\mathrm{TDep}}=\sum_{k=\mathrm{CCN}}^{k_{\max }} \operatorname{Pr}_{\mathrm{CCN}, k} \operatorname{Pr}_{\mathrm{Dep}, k}
$$

In this equation, $P_{\mathrm{TDep}}$ is the probability that a particle just reaching the $\mathrm{CCN}$ cutoff will be removed by deposition, $\mathrm{CCN}$ is the lowest size section in which the particles are $\mathrm{CCN}$-sized, $P r_{\mathrm{CCN}, k}$ is the probability that the particle will grow from size section CCN to size section $k$, and $P r_{\text {Dep }, k}$ is the probability that a particle in bin $k$ will be removed by deposition before growing to the next size bin. We define the $\mathrm{CCN}$ formation efficiency from ultrafine particles as:

Eff $=P r_{U F, \mathrm{CCN}} P r_{\mathrm{TDep}}$

Combining Eqs. (9) through (11) yields:

$\Delta \mathrm{CCN}=\operatorname{Eff} \tau_{\mathrm{dsnk}} \Delta S$

In this equation, $\tau_{\mathrm{dsnk}}$ is the number lifetime of $\mathrm{CCN}$-sized particles with respect to deposition. For regions with low $\mathrm{CCN}$ concentrations, Eff is approximately $\operatorname{Pr}_{U F, \mathrm{CCN}}$, but in regions where the concentrations of $\mathrm{CCN}$ are high, Eff will be smaller due to removal of $\mathrm{CCN}$ by coagulation with larger particles.

\section{Evaluation of the PUG model}

We tested the PUG model's calculation of the efficiency against the same calculation done using a box model with a full description of aerosol microphysics. This evaluation spanned a wide variety of aerosol background distributions and condensable gas concentrations. In this section we also explore the importance of the various growth and sink processes.

\subsection{Box model}

The box model computes condensation and coagulation using the TwO-Moment Aerosol Sectional (TOMAS) microphysics model that has been used in the Goddard Institute for Space Studies General Circulation Model II-prime (GISS GCM II-prime) (Adams and Seinfeld, 2003, 2002; Pierce and Adams, 2006). In the box model, a steady flux of an aerosol distribution enters the box where the deposition lifetime is specified. We assume a constant condensable gas concentration. The model is initialized from an empty box until a steady-state aerosol size distribution is reached. This steadystate distribution represents the resultant distribution in a well-mixed atmosphere if aerosol inputs, low-volatility gas concentrations and deposition rates are constant with time.

The $\mathrm{CCN}$ formation efficiency of a given ultrafine particle size is found from two box model simulations. In the "base case" simulation, the aerosol influx, condensable gas concentration and deposition rates are chosen and a steady-state distribution is found. In the "ultrafine" simulation, a small additional flux of the given size of ultrafine particles is added to the base case influx causing a slight increase in the number of $\mathrm{CCN}$ in the resultant steady-state distribution. The CCN formation efficiency formation is calculated from Eq. (12).

A disadvantage of the TOMAS box model compared to PUG is that a given aerosol background distribution cannot be specified a priori. In TOMAS, the number distribution of the aerosol influx may be specified, but the calculated efficiency corresponds to the resulting steady-state size distribution in the box. This disadvantage, however, does not prevent it from being a tool to evaluate the PUG model. 
Table 1. Typical aerosol size distributions in various areas in the atmosphere as described by Jaenicke (1993) and used in PUG model evaluation.

\begin{tabular}{|c|c|c|c|c|c|c|c|c|c|}
\hline \multirow[b]{2}{*}{ Type } & \multicolumn{3}{|c|}{ Mode I } & \multicolumn{3}{|c|}{ Mode II } & \multicolumn{3}{|c|}{ Mode III } \\
\hline & $\begin{array}{c}\mathrm{N} \\
{\left[\mathrm{cm}^{-3}\right]}\end{array}$ & $\begin{array}{c}\mathrm{D}_{p} \\
{[\mu \mathrm{m}]}\end{array}$ & $\log \sigma$ & $\begin{array}{c}\mathrm{N} \\
{\left[\mathrm{cm}^{-3}\right]}\end{array}$ & $\begin{array}{c}\mathrm{D}_{p} \\
{[\mu \mathrm{m}]}\end{array}$ & $\log \sigma$ & $\begin{array}{c}\mathrm{N} \\
{\left[\mathrm{cm}^{-3}\right]}\end{array}$ & $\begin{array}{c}\mathrm{D}_{p} \\
{[\mu \mathrm{m}]}\end{array}$ & $\log \sigma$ \\
\hline Urban & $9.93 \times 104$ & 0.013 & 0.245 & $1.11 \times 103$ & 0.014 & 0.666 & $3.64 \times 104$ & 0.05 & 0.337 \\
\hline Marine & 133 & 0.008 & 0.657 & 66.6 & 0.266 & 0.21 & 3.1 & 0.58 & 0.396 \\
\hline Remote Continental & 3200 & 0.02 & 0.161 & 2900 & 0.116 & 0.217 & 0.3 & 1.8 & 0.38 \\
\hline Free Troposphere & 129 & 0.007 & 0.645 & 59.7 & 0.25 & 0.253 & 63.5 & 0.52 & 0.425 \\
\hline
\end{tabular}

\subsection{Testing fields for PUG and box models}

To test the PUG model and the box model against each other, efficiencies were calculated for a wide variety of aerosol backgrounds and $\mathrm{H}_{2} \mathrm{SO}_{4}$ concentrations. $\mathrm{H}_{2} \mathrm{SO}_{4}$ is chosen here as a representative condensable gas to facilitate the comparison of the two models. This choice is not meant to imply anything about its atmospheric importance relative to other condensable gases (e.g. SOA). Deposition lifetimes were taken to be seven days for all aerosol sizes. The aerosol distributions used for the air that flows into to the TOMAS box were the urban, marine, remote continental and free troposphere distributions from Table 1 (Jaenicke, 1993). The steady-state ambient aerosol distributions in the box model are different from the input distributions in Table 1 due to processing by aerosol microphysics, mostly a reduction in the number of the smallest particles (dry diameter $<50 \mathrm{~nm}$ ) via coagulation. To compare the PUG model to the TOMAS box model using the same ambient aerosol fields, the steadystate distributions from the box model are used as input into the PUG model. The total number of particles, $N$, in each of the input size distributions into the box model was scaled by a factor of $0.1,0.3,1,3$ and 10 to give 20 different aerosol backgrounds. A total of 17 different $\mathrm{H}_{2} \mathrm{SO}_{4}$ concentrations were used between 0.001 and 10 ppt. The $\mathrm{H}_{2} \mathrm{SO}_{4}$ accommodation coefficient was assumed to be 1 . Aerosol density and water uptake are calculated as if the particles were ammonium bisulfate (Nenes, et al., 1998; Tang and Munkelwitz, 1994). The relative humidity, temperature and pressure were taken to be $80 \%, 273 \mathrm{~K}$ and 1 bar, respectively.

\subsection{Results of the comparison}

Figure 3 shows the $\mathrm{CCN}$ formation efficiency of $30 \mathrm{~nm}$ (dry diameter) particles when the CCN cutoff diameter is $90 \mathrm{~nm}$. The $90 \mathrm{~nm}$ cutoff was used because it corresponded to one of the mass doubling sizes in the model and is within the range of $\mathrm{CCN}$ cutoff diameters in stratus clouds. A CCN cutoff size in between the doubling sizes of the model may also be used by modifying the equations in Sect. 3; however the $90 \mathrm{~nm}$ cutoff was used here for simplicity. The four panels represent four different $\mathrm{H}_{2} \mathrm{SO}_{4}$ concentrations. The $\mathrm{x}$ axis is the coagulation sink timescale for the original $30 \mathrm{~nm}$ particle. The efficiency in each plot asymptotically reaches a maximum value when the coagulation sink timescale becomes much longer than the 7 day deposition timescale such that deposition becomes the dominant removal mechanism. Note that the asymptotic maximum is much less than one in the $0.1 \mathrm{ppt}$ panel, implying that the 7-day deposition lifetime is significantly faster than the time it takes the ultrafine particles to grow to the $\mathrm{CCN}$ sizes. As expected, the maximum probabilities in each plot increase as the $\mathrm{H}_{2} \mathrm{SO}_{4}$ concentration increases. The shape of the curve is approximately sigmoidal, and the steep portion of the curve occurs when the coagulational scavenging process and the condensational growth process are occurring at comparable rates.

CCN formation efficiencies from the box model and PUG model agree within $10 \%$ with larger relative errors occurring at lower efficiencies. Differences occur between the models due to differences in the numerical solution techniques of the aerosol microphysical processes and how the size distributions are discretized. The PUG model is easier to apply to many applications than the box model because of its ability to specify an aerosol background. For this reason, we will use the PUG model for the applications presented throughout the rest of this paper.

\subsection{Importance of growth and removal processes}

Additionally, a variation of the PUG model, PUG-Coarse (PUGC), was also tested. The PUGC model is similar to the standard PUG model with the exception that the aerosol background is represented only by coarse particles with $10 \mu \mathrm{m}$ dry diameter, the largest particle size represented in this work. PUGC removes the influence of growth by coagulation with smaller particles, isolating the effect of this growth mechanism when compared to the standard PUG model. PUGC calculations spanned a wide range of conditions using aerosol backgrounds that give similar coagulation sink timescales as those described in the previous section.

Figure 4 is similar to Fig. 3, but shows the results of the PUG and PUGC simulations. In Fig. 4, the ambient aerosol distributions used in the PUG model are those used in Table 1 (scaled in magnitude by the same 5 factors described in the last section), rather than the steady-state distributions from 
(a) $0.1 \mathrm{ppt} \mathrm{H}_{2} \mathrm{SO}_{4}$

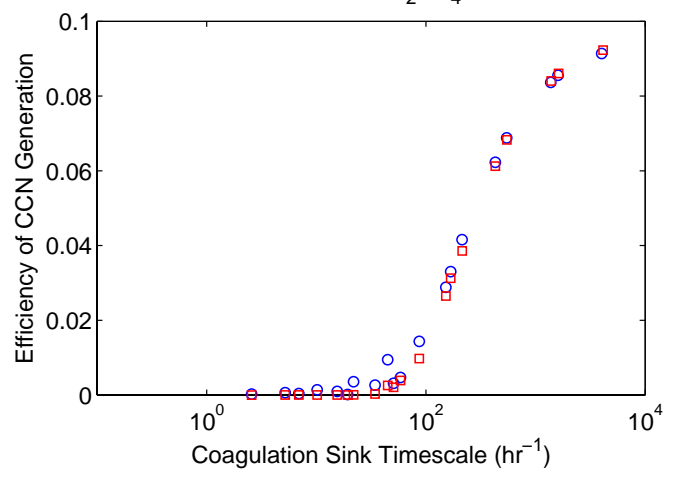

(c) $1 \mathrm{ppt} \mathrm{H}_{2} \mathrm{O}_{4}$

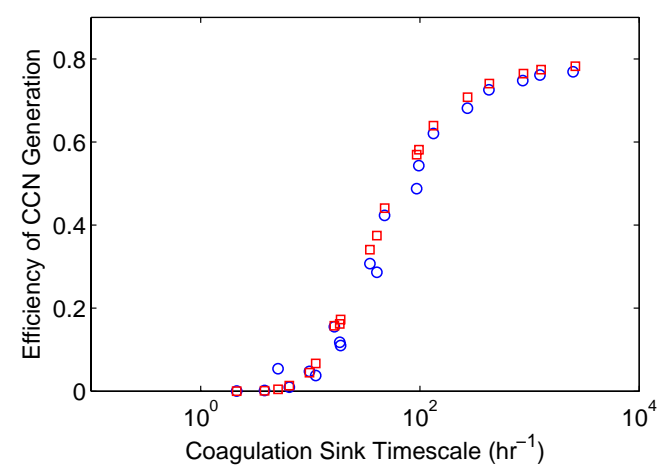

(b) $0.4 \mathrm{ppt} \mathrm{H}_{2} \mathrm{SO}_{4}$

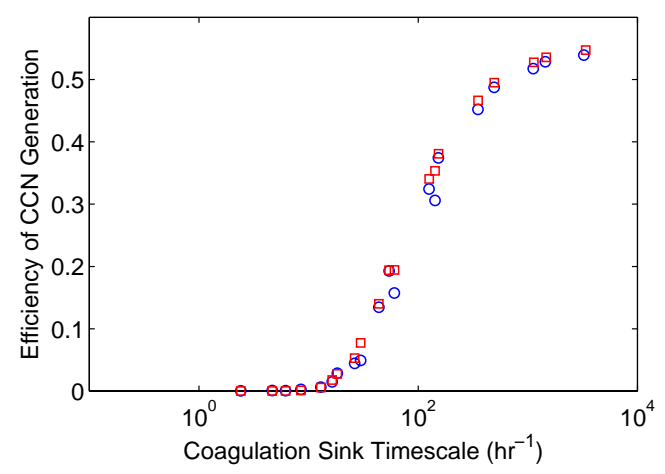

(d) $4 \mathrm{ppt} \mathrm{H}_{2} \mathrm{SO}_{4}$

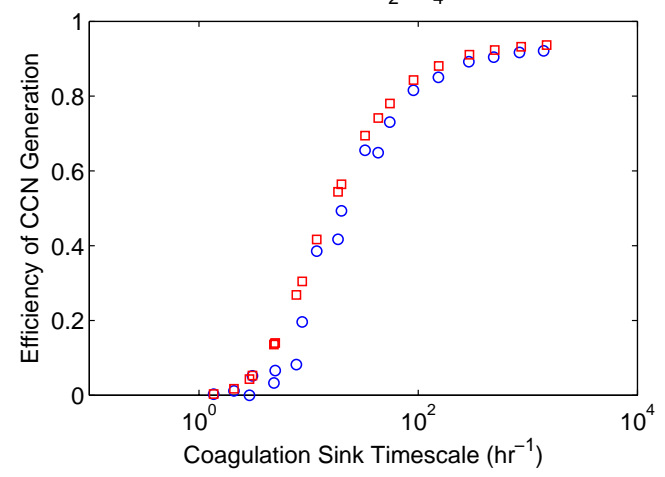

Fig. 3. Comparison of the CCN formation efficiency of $30 \mathrm{~nm}$ diameter ultrafine particles for a CCN cutoff diameter of $90 \mathrm{~nm}$ between the PUG model and the TOMAS box model ( $\mathrm{y}$-axis limits vary between panels). The coagulation sink timescale plotted on the $\mathrm{x}$-axis is the timescale for the original $30 \mathrm{~nm}$ particle. The squares are the PUG model results and the circles are TOMAS box model results.

the TOMAS box model, which reduced the number of small particles. The standard PUG simulations and the PUGC simulations agree very well for nearly all points implying that coagulation with smaller particles is usually a minor growth process. An exception to this is the five solid square points in each figure, corresponding to the five scaled urban backgrounds described earlier. The urban background distributions have a large number of particles in the $10-30 \mathrm{~nm}$ range, and coagulation of these smaller particles with the ultrafine particle in question causes significant growth. The results described here show that condensation is generally the dominant growth mechanism, and only when there are very large numbers of small ultrafine particles will coagulational growth play a major role.

When the results of a given simulation lay on the asymptotic part of the curve towards the right of each panel in Fig. 4, the deposition sink dominates coagulational scavenging and controls the $\mathrm{CCN}$ formation efficiency (i.e. the efficiency does not increase even when the coagulation sink diminishes). This occurs for the simulations with longest coagulation sink timescales. Because the points are largely not in the asymptotic part of the curve we conclude that the coagulation sink timescale is generally the dominant removal mechanism for ultrafine aerosol number. However, for larger particles, generally those already past the $\mathrm{CCN}$ cutoff diameter, the coagulation sink timescale increases and the deposition timescale becomes the dominant removal mechanism.

\section{Applications and results}

\subsection{Tropospheric CCN formation efficiencies}

Figure 5 shows contour plots of the $\mathrm{CCN}$ formation efficiency of $30 \mathrm{~nm}$ dry diameter particles when the CCN cutoff diameter is $90 \mathrm{~nm}$. This is shown as a function of the combined sink timescales (coagulation sink plus deposition sink) and the combined growth timescales (condensation growth plus coagulational growth). The plotted timescales represent the timescales for the original $30 \mathrm{~nm}$ particle. For reference, when a $30 \mathrm{~nm}$ diameter particle doubles in mass, it is then $38 \mathrm{~nm}$ in diameter (assuming the density does not change). Therefore, the growth rate of the $30 \mathrm{~nm}$ particle in $\mathrm{nm} \mathrm{h}^{-1}$ may be approximated by dividing $8 \mathrm{~nm}$ by the mass doubling timescale (e.g. for a $10 \mathrm{~h}$ timescale the growth rate would be $0.8 \mathrm{~nm} \mathrm{~h}^{-1}$ ). The efficiency depends on the evolution of the coagulation timescales as the particle grows, which depends on the specified size distribution. Here we have used the PUGC model to create a smooth efficiency surface. Using 
(a) $0.1 \mathrm{ppt} \mathrm{H}_{2} \mathrm{SO}_{4}$

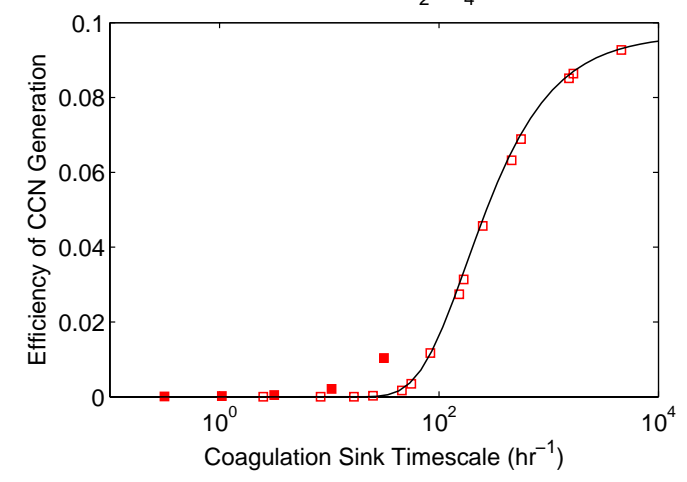

(c) $1 \mathrm{ppt} \mathrm{HSO}_{4}$

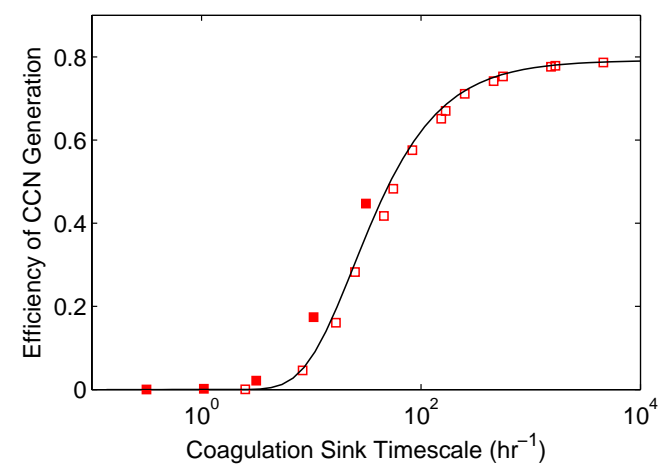

(b) $0.4 \mathrm{ppt} \mathrm{H}_{2} \mathrm{SO}_{4}$

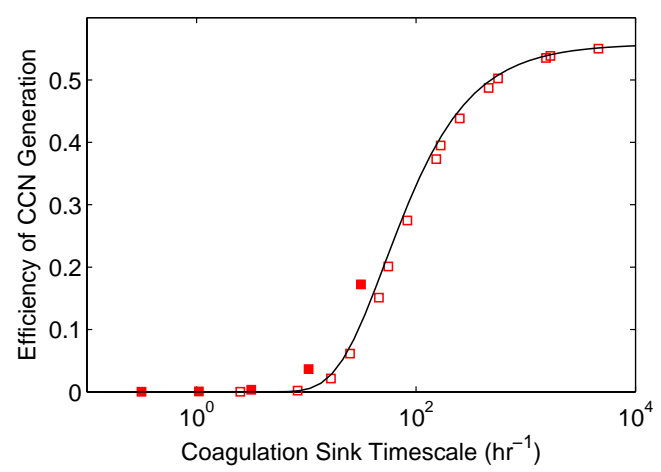

(d) 4 ppt $\mathrm{H}_{2} \mathrm{OO}_{4}$

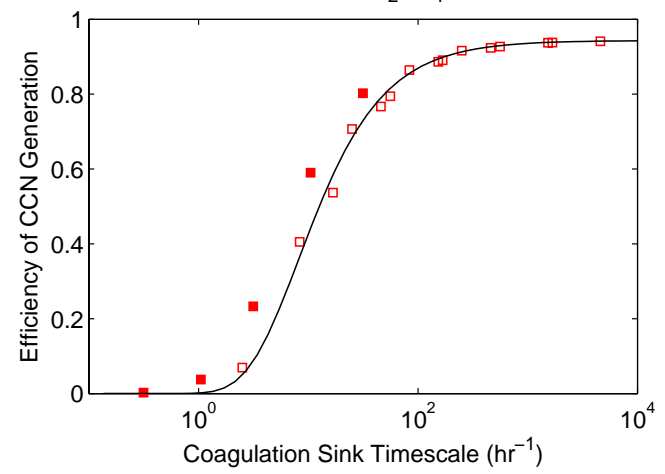

Fig. 4. Comparison the CCN formation efficiency of $30 \mathrm{~nm}$ diameter ultrafine particles for a CCN cutoff diameter of $90 \mathrm{~nm}$ between the PUG and PUGC models (y-axis limits vary between panels). The coagulation sink timescale plotted on the $\mathrm{x}$-axis is the timescale for the original $30 \mathrm{~nm}$ particle. The squares are the PUG model results (solid squares are for the urban distribution) and the black line is the PUGC results.

other size distributions will have only a minor effect on the predicted efficiency. It is assumed that the aerosol composition does not change as it grows such that the aerosol water mass per unit dry mass remains constant and the aerosol density remains constant. The shape of the efficiency distribution is asymptotic towards one for short growth timescales and long sink timescales and asymptotic towards zero at long growth timescales and short sink timescales.

Overlaid on the contour plot are seasonally averaged growth and sink timescales from grid-cells in various atmospheric locations in the GISS GCM II-prime with online aerosol microphysics (Adams and Seinfeld, 2003, 2002; Pierce and Adams, 2006). In the simulation used, there are no carbonaceous or dust particles, only sulfate and sea-salt aerosol, and $\mathrm{H}_{2} \mathrm{SO}_{4}$ is the only condensable gas; thus, the timescales and efficiencies shown here are not completely representative of the real atmosphere. However, we expect that the main points determined from this exercise regarding the variability of $\mathrm{CCN}$ formation efficiency within regions of the atmosphere and between regions will still be valid when all of the species are included. The values used were produced by the CLRK simulation in Pierce and Adams (2006) and represent our "best guess" simulation of sulfate and seasalt microphysics. Time-averaged aerosol size distributions and $\mathrm{H}_{2} \mathrm{SO}_{4}$ concentrations from various parts of the atmosphere, taken from GCM grid cells within the spatial coordinates described below, were used to find the growth and removal times of the $30 \mathrm{~nm}$ particle. It should be noted that the timescales plotted are for specific locations (grid cells in the GCM) and the corresponding CCN efficiency applies only for that location. As particles are transported throughout their lifetime, the efficiency will change with their location. Boundary layer aerosol size distributions and $\mathrm{H}_{2} \mathrm{SO}_{4}$ concentrations were taken from the lowest model layer (below $\sim 930 \mathrm{mb}$ ) and free troposphere values were taken from model layers between 720 and $250 \mathrm{mb}$. The tropical regions use timescales from grid-cells between $12^{\circ} \mathrm{S}$ and $12^{\circ} \mathrm{N}$. The polluted boundary layer timescales were taken from surface grid-cells in the Eastern USA $\left(75^{\circ} \mathrm{W}\right.$ to $90^{\circ} \mathrm{W}$ and $32^{\circ} \mathrm{N}$ to $\left.44^{\circ} \mathrm{N}\right)$ and Western Europe $\left(10^{\circ} \mathrm{E}\right.$ to $25^{\circ} \mathrm{E}$ and $44^{\circ} \mathrm{N}$ to $56^{\circ} \mathrm{N}$ ), the remote continental timescales were taken from the surface grid-cells in the Northwest USA/Western Canada $\left(100^{\circ} \mathrm{W}\right.$ to $120^{\circ} \mathrm{W}$ and $36^{\circ} \mathrm{N}$ to $\left.60^{\circ} \mathrm{N}\right)$ and Siberia $\left(70^{\circ} \mathrm{E}\right.$ to $120^{\circ} \mathrm{E}$ and $48^{\circ} \mathrm{N}$ to $64^{\circ} \mathrm{N}$ ) and the Southern Ocean timescales were taken from all surface grid-cells from $48^{\circ} \mathrm{S}$ to $64^{\circ} \mathrm{S}$.

Figure 5 shows that, for the sea-salt and sulfate system, the $\mathrm{CCN}$ formation efficiency in the atmosphere varies between 

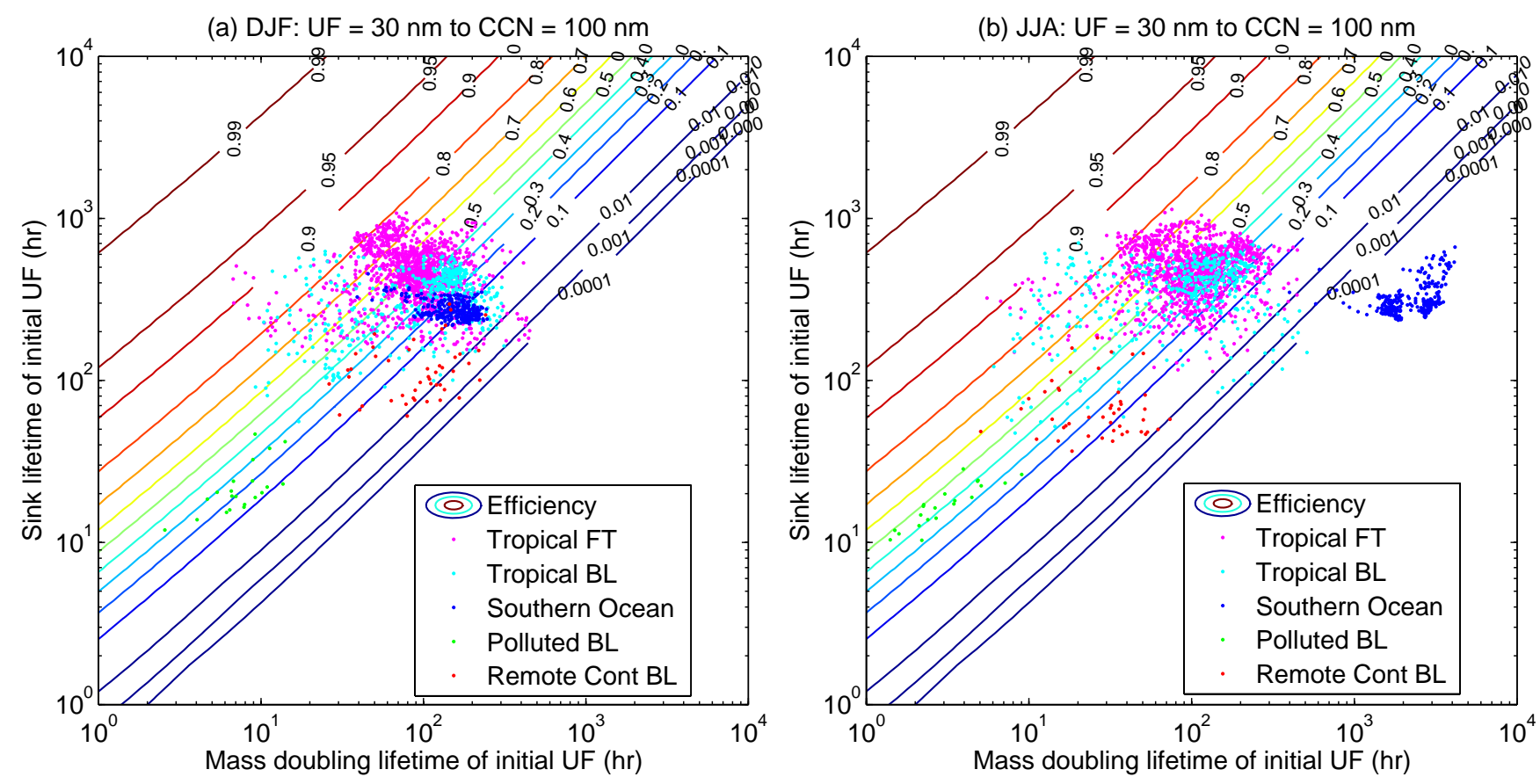

Fig. 5. The CCN formation efficiency for $30 \mathrm{~nm}$ diameter ultrafine particles with a CCN cutoff diameter of $90 \mathrm{~nm}$ plotted as a function of the sink and doubling lifetimes. Overlaid are the timescales for various regions from the CLRK simulation in Pierce and Adams (2006) average for (a) December, January and February and (b) June, July and August.

very low $(<0.1 \%)$ to high $(\sim 90 \%)$ for growth from $30 \mathrm{~nm}$ to $90 \mathrm{~nm}$. Different ultrafine diameters and CCN cutoff diameters lead to different ranges of efficiencies but with variation over similar orders of magnitude. As would be expected, the efficiencies in the tropical regions do not have much seasonal variation. Both the tropical boundary layer and the tropical free troposphere have a large span of predicted efficiencies of $\mathrm{CCN}$ generation (from about $1 \%$ to $90 \%$ ). The $\mathrm{CCN}$ formation efficiency for each mid-latitude region is higher during its summer than winter. This is most notable for the Southern Ocean that has very low efficiencies during JJA due to slow conversion of $\mathrm{SO}_{2}$ to $\mathrm{H}_{2} \mathrm{SO}_{4}$ in these higher latitudes.

Growth and sink timescales tend to be somewhat correlated with the shortest growth timescales (i.e. fast condensational growth) occurring with the shortest sink timescales (i.e. efficient coagulational scavenging) in the polluted continental boundary layer. Due to this weak correlation across most atmospheric regions regions (ignoring the Southern Ocean in the winter), the efficiencies of CCN generation in the mid-latitude regions generally are bounded between $1 \%$ and $40 \%$ with a number of outliers in the remote continental backgrounds. In general, the variability of the efficiency within each atmospheric regime shown here is nearly as large as the variability between the different atmospheric regions. This makes it difficult to determine whether various regions of the atmosphere are more efficient at generating $\mathrm{CCN}$ from ultrafine particles than other regions.
However, it is clear that during JJA the marine boundary layer above the Southern Ocean is inefficient at generating $\mathrm{CCN}$. In general, areas with little or no solar irradiance will have low efficiencies. The efficiency in the tropics (boundary layer and free troposphere) is generally larger than the mid-latitude locations and the tropical free troposphere is somewhat more efficient at generating $\mathrm{CCN}$ than the tropical boundary layer. This may mean that nucleation in the free troposphere is more efficient at generating $\mathrm{CCN}$ than elsewhere in the atmosphere; however, without the large number of carbonaceous particles from biomass burning in the tropics and fossil fuel combustion in the $\mathrm{NH}$ mid-latitudes, these results are inconclusive.

\subsection{Uncertainty in $\mathrm{CCN}$ from uncertainty in ultrafine emis- sions}

In general, greater emphasis has been placed on measuring the total mass of primary particle emissions than on measuring their number or size distributions. Emissions size distributions must be assumed in global models to make CCN predictions from the mass emissions, and errors in the assumed size distribution will lead to errors in predicted CCN. The uncertainty in $\mathrm{CCN}$ generation may be found using the PUG model to determine the number of $\mathrm{CCN}$ that result from the addition of an uncertain distribution of ultrafine particles. 
(a) Urban

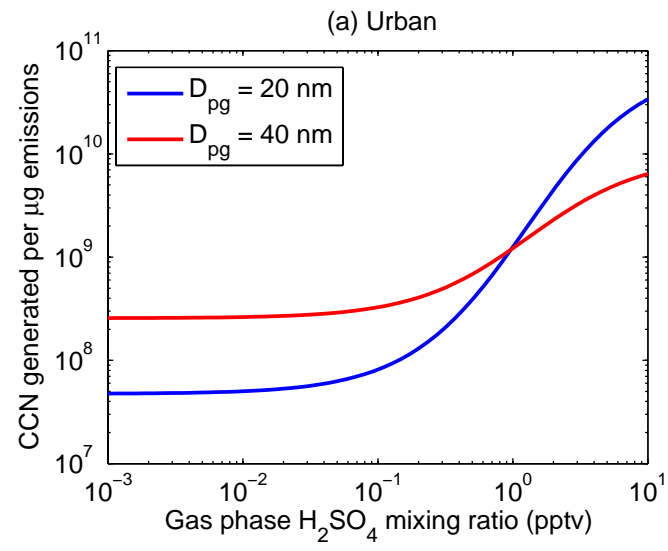

(c) Remote Continental

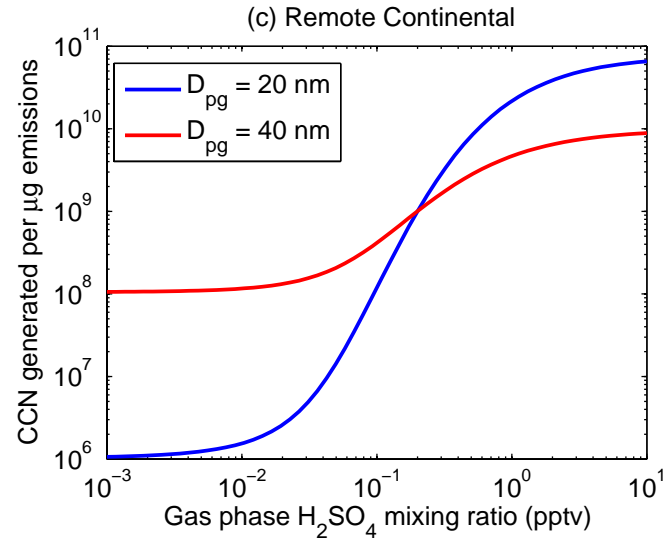

(b) Remote Continental

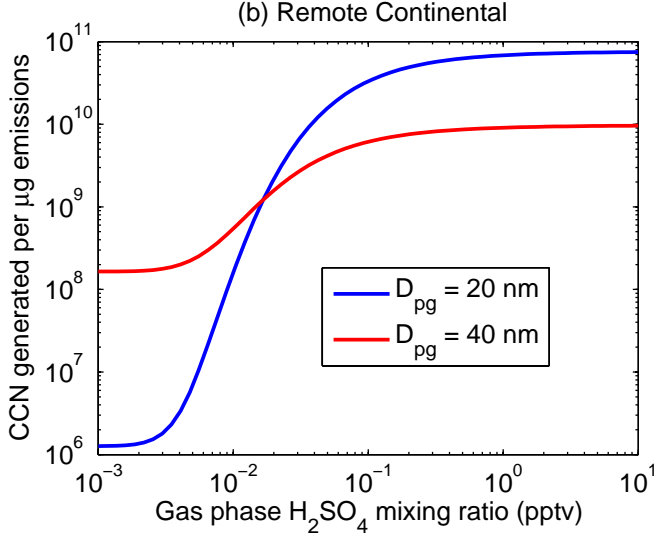

(d) Free Troposphere

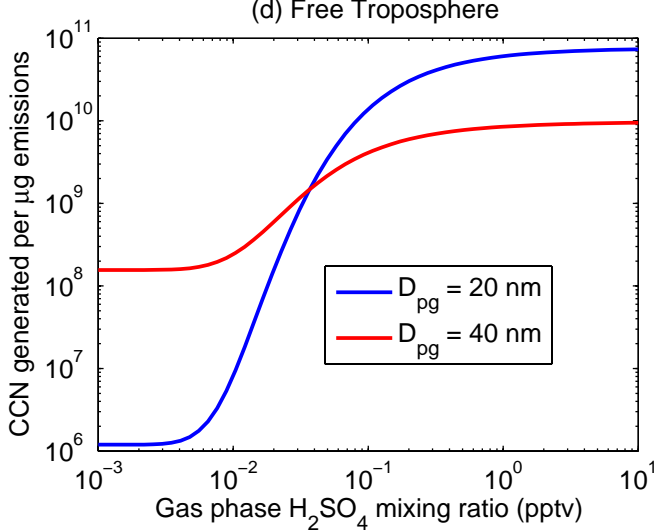

Fig. 6. Number of CCN generated per $\mu \mathrm{g}$ of emissions from two size distributions of primary ultrafine aerosol as a function of the gas phase $\mathrm{H}_{2} \mathrm{SO}_{4}$ concentration under four different aerosol backgrounds. The lognormal parameters describing the two emitted number distributions are $\mathrm{D}_{p g}=20 \mathrm{~nm}, \sigma_{g}=1.41$ and $\mathrm{D}_{p g}=40 \mathrm{~nm}, \sigma_{g}=1.41$.

The number of CCN formed from a distribution of new ultrafine particles is:

$G_{\mathrm{CCN}}=\int_{0}^{\infty} \operatorname{Eff}\left(D_{p}\right) N_{U F}\left(D_{p}\right) d D_{p}$

In this equation, $G_{\mathrm{CCN}}$ is the number of $\mathrm{CCN}$ generated, $\operatorname{Eff}\left(D_{p}\right)$ is the efficiency of a new ultrafine particle generating a CCN as a function of the size of the new particle and $N_{U F}\left(D_{p}\right)$ is the number size distribution of the new particles. In the discrete form of the PUG model, Eq. (13) takes the following form:

$G_{\mathrm{CCN}}=\sum_{k=1}^{k_{\max }} \operatorname{Eff}_{k} N_{U F, k}$

In this equation, $k$ is the size-section, $k_{\max }$ is the largest size section, $\mathrm{Eff}_{k}$ is the efficiency of a particle in size-section $k$ generating a CCN and $N_{U F, k}$ is the number of new particles in size-section $k$. This method includes emissions into size sections larger than the CCN size cutoff and, although these are not ultrafine particles by our definition, the $\mathrm{CCN}$ formation efficiency of these new particles may still be less than one if the $\mathrm{CCN}$-sized particles have a short lifetime (see Sect. 3.2).

The uncertainty in $\mathrm{CCN}$ formation due to uncertainty in new ultrafine amount and size distribution can be found by evaluating Eq. (14) multiple times, spanning the range of possible emissions amounts and size distributions. This is shown by exploring an example where one $\mu \mathrm{g}$ of ultrafine aerosol is emitted to the atmosphere with an uncertain emission size distribution. It is assumed that the emissions follow a lognormal size distribution where $\sigma_{g}=1.4$. We assume it is known that the geometric mean diameter, $\mathrm{D}_{p g}$, of the mode lies between $20 \mathrm{~nm}$ and $40 \mathrm{~nm}$, roughly corresponding to our knowledge of urban traffic emissions. Although traffic emissions are primarily composed of carbonaceous species, for simplicity we have assumed that all particles are ammonium bisulfate. This does not affect our conclusions about the uncertainty of $\mathrm{CCN}$ generation. Calculations were done for $80 \%$ relative humidity at $273 \mathrm{~K}$ and 1 bar. The deposition lifetimes used here are 70 days for all ultrafine particles and 5 days for all $\mathrm{CCN}$ particles. These values are representative 


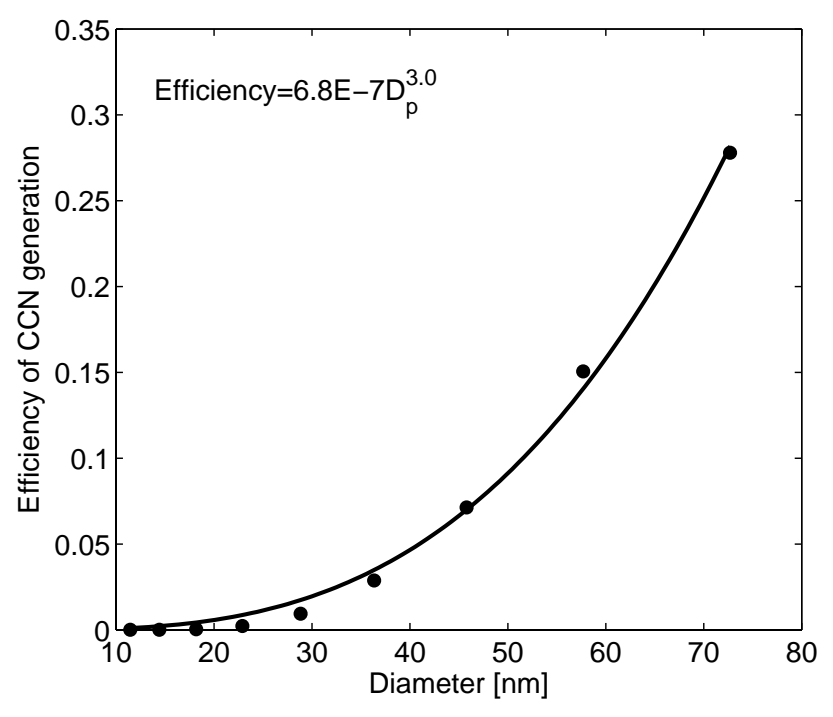

Fig. 7. The CCN formation efficiency as a function of the initial dry diameter of the ultrafine particle $(\mathrm{CCN}$ cutoff diameter $=90 \mathrm{~nm})$. An "urban aerosol" (Table 1) background was used and a $\mathrm{H}_{2} \mathrm{SO}_{4}$ concentration of $0.5 \mathrm{pptv}$. The temperature is $273 \mathrm{~K}$, pressure is 1 bar and RH is $80 \%$. Circles are the probabilities predicted by the PUG model and the line is the best fit to Eq. (15).

of particles in the global model in the work by Adams and Seinfeld (2002) and Pierce and Adams (2006).

Figure 6 shows the number of CCN (with cutoff diameter of $90 \mathrm{~nm}$ ) generated from these emissions as a function of $\mathrm{H}_{2} \mathrm{SO}_{4}$ concentration for four different aerosol backgrounds. $\mathrm{H}_{2} \mathrm{SO}_{4}$ is used here as a representative condensable gas to help illustrate the uncertainties in CCN generation. The uncertainty in $\mathrm{CCN}$ generated by the ultrafine emissions is the difference between the two lines on each plot, and there are conditions (albeit extremes) where the differences in number of $\mathrm{CCN}$ formed are 1-2 orders of magnitude. The $20 \mathrm{~nm}$ peak has eight times more particles per kilogram than the $40 \mathrm{~nm}$ peak. In the limit of very high condensable gas concentrations, all ultrafine particles grow to become CCN. Therefore, more CCN are formed from the size distribution with the larger number of particles whenever the condensable gas concentration is high. Conversely, more $\mathrm{CCN}$ are generated by the $40 \mathrm{~nm}$ peak mode at low condensable gas concentrations because the emitted particles do not have to grow as much. For the aerosol backgrounds with low amounts of accumulation-mode sized particles such as the marine and free troposphere distributions, the coagulation sink timescale for the ultrafine particles are long, so it does not require much condensable gas to grow the particles in the smaller distribution to CCN sizes before they are removed. For the urban distribution that contains many accumulation mode particles, more condensable gas is required for growth before removal.

These results show that, except for the points in Fig. 6 where the two curves cross, the total mass of primary par-
Table 2. Values of $B$ for several aerosol backgrounds and corresponding $\mathrm{H}_{2} \mathrm{SO}_{4}$ concentrations.

\begin{tabular}{lccc}
\hline Background & $\begin{array}{c}\text { Particles with } \\
\mathrm{Dp}>100 \mathrm{~nm} \\
{\left[\mathrm{~cm}^{-3} \mathrm{STP}\right]}\end{array}$ & $\begin{array}{c}\mathrm{H}_{2} \mathrm{SO}_{4} \\
{[\mathrm{ppt}]}\end{array}$ & $B$ \\
\hline Urban & 6500 & $1-10$ & $0.6-2.3$ \\
Marine & 74 & $0.01-0.1$ & $0.6-4.0$ \\
Remote Continental & 1700 & $0.1-1$ & $0.7-4.0$ \\
Free Troposphere & 120 & $0.05-0.5$ & $0.3-2.0$ \\
\hline
\end{tabular}

Temperature $=273$ K, Pressure $=1$ bar, $\mathrm{RH}=80 \%$

ticles is a poor predictor of $\mathrm{CCN}$ formation. However, it is possible that another moment of the ultrafine emissions size distribution (e.g. total number, surface area, etc.) may be a robust predictor of $\mathrm{CCN}$ generation. This simplification would occur if the CCN formation efficiency varies with ultrafine particle size in a way that fits well to the following equation.

$\mathrm{Eff}=A \cdot D_{p}^{B}$

In this equation, $A$ is a fitted pre-exponential factor, $D_{p}$ is the initial diameter of the ultrafine and $B$ is a fitted exponent. The value of $B$ determines if the number of $\mathrm{CCN}$ generated from ultrafine emissions may be well predicted by a single moment of the aerosol distribution. For example, if $B$ is two and Eq. (15) is substituted into Eq. (13), the number of CCN generated is a function of only the total surface area of the emissions. Similarly, if $B$ is one or three, the number of $\mathrm{CCN}$ generated will be a function of only the total diameter of particles or the total mass of particles, respectively. In the limit of quick aerosol growth, total new ultrafine number becomes the best predictor of CCN generated and is represented in Eq. (15) as $B$ approaches zero.

To examine if any single moment of the aerosol size distribution gives robust results, we explore how the $\mathrm{CCN}$ formation efficiency depends on its initial diameter for different atmospheric regimes. For a given aerosol background size distribution and condensable gas concentration, the $\mathrm{CCN}$ formation efficiency of ultrafine particles is found for a number of ultrafine diameters and the values of $A$ and $B$ in Eq. (15) are found though fitting these data. An example of this fit for the urban distribution with an $\mathrm{H}_{2} \mathrm{SO}_{4}$ concentration of $0.5 \mathrm{ppt}$ is shown in Fig. 7. For the conditions shown in Fig. 7, $B$ equals 3.0, so an accurate knowledge of the total mass of the emitted ultrafine distribution would minimize the error in the CCN formation.

To determine if one of the moments of the size distribution of ultrafine particles is best for determining the contribution to $\mathrm{CCN}$, we repeated the above procedure for a number of realistic aerosol backgrounds and their associated condensable gas concentrations (or condensation growth timescale). 
Because the condensable gas concentration (and corresponding condensation growth timescale) is difficult to measure, we will use a range for the $\mathrm{H}_{2} \mathrm{SO}_{4}$ concentrations for each of the four Jaenicke (1993) distributions described earlier. We extracted the ranges of $\mathrm{H}_{2} \mathrm{SO}_{4}$ from runs in the GISS-GCM II-prime with TOMAS (Pierce and Adams, 2006). Information on the various aerosol backgrounds, gas concentrations and resulting values of $B$ are given in Table 2 .

It is clear in Table 2 that the values of $B$ vary greatly depending on the $\mathrm{H}_{2} \mathrm{SO}_{4}$ concentrations and atmospheric region. Therefore, it appears there is no single moment of the aerosol size distribution that consistently predicts the number of $\mathrm{CCN}$ generated from ultrafine particles. In this investigation, $\mathrm{H}_{2} \mathrm{SO}_{4}$ concentrations were given an order of magnitude uncertainty for each aerosol background; a smaller range of $\mathrm{H}_{2} \mathrm{SO}_{4}$ concentrations would result in a smaller range of $B$ values. The smaller range of $\mathrm{H}_{2} \mathrm{SO}_{4}$ concentrations may be justified if more precursor gases (i.e. $\mathrm{SO}_{2}$ ) tend to be emitted in areas of higher aerosol surface area. While this would cause the uncertainty in $B$ within each region to be reduced, there would likely still be variation in $B$ between regions.

It is clear from this analysis that measuring total number will in no case be the best predictor of the number of $\mathrm{CCN}$ generated. Also, it seems unlikely that the other moments of the aerosol size distribution will consistently be good predictors of CCN generation. Based on this analysis, two or three parameters of the emitted size distribution, if not the full distribution itself, should be used in order to predict accurately the ultrafine particle's impact on $\mathrm{CCN}$.

\section{Conclusions}

This paper has explored the efficiency with which new ultrafine particles grow to generate $\mathrm{CCN}$ in the atmosphere. Understanding the formation of $\mathrm{CCN}$ from new particles is a crucial step to understanding the CCN budget and the influence of humans on climate through the modification of cloud radiative properties. To help answer the questions regarding $\mathrm{CCN}$ formation, we have developed the Probability of Ultrafine particle Growth (PUG) model to predict the CCN formation efficiency of ultrafine particles. User-specified inputs to this model are a fixed aerosol background size distribution, a constant condensable gas concentration and aerosol deposition lifetimes. The PUG model closely matched predicted $\mathrm{CCN}$ formation efficiencies of an aerosol box model with online microphysics. The PUG model has advantages over the box model because the aerosol background may be specified as an input, is faster to run, and can be used easily to estimate $\mathrm{CCN}$ formation efficiency across a variety of atmospheric regimes.

It was found that, in atmospheric conditions, condensation is generally the dominant growth mechanism of ultrafine particles. Growth of ultrafine particles due to coagula- tion with smaller particles may be ignored unless the number concentration of ultrafine particles is high (ultrafine concentration $>10^{4} \mathrm{~cm}^{-3}$ ). Using the aerosol size distributions published by Jaenicke (1993), we found that the particle growth from coagulation between ultrafine particles cannot be ignored when the ambient aerosol size distribution is similar to their "urban" distribution regardless of the condensation rate. In nearly all regions of the atmosphere, coagulation with larger particles is the dominant removal mechanism for ultrafine aerosol number. In the most remote regions of the atmosphere (where accumulation mode particle concentrations are less than $50 \mathrm{~cm}^{-3}$ ), the coagulational loss timescale may be long enough to be comparable to the deposition rate of ultrafine particles (which is usually on the order of tens of days).

The range of efficiencies of $\mathrm{CCN}$ formation was estimated using input data from a global model with online sulfate and sea-salt aerosol microphysics. The CCN formation efficiency was found to range from very low $(<0.1 \%)$ to high ( $\sim 90 \%$ ) depending on the size that the aerosol was emitted and the characteristic growth and sink timescales of the region of the atmosphere where the particle exists. There is a weak correlation between the removal timescale and the growth timescale that keeps a large fraction of the efficiencies of $\mathrm{CCN}$ generation in the mid-latitude boundary layer between about $1 \%$ and $40 \%$ for an ultrafine size of $30 \mathrm{~nm}$ and a CCN cutoff diameter of $90 \mathrm{~nm}$. The CCN formation efficiency increases in the mid-latitude regions from the winter to the summer. In regions where there is little to no solar irradiance, the $\mathrm{CCN}$ formation efficiency is very low due to low condensation rates. In general, the scatter in the $\mathrm{CCN}$ formation efficiency within individual regions of the atmosphere is comparable to the variability in the efficiency between the various regions.

The uncertainty in the number of $\mathrm{CCN}$ generated due to uncertainty in the size distribution of ultrafine particle emissions was assessed using the PUG model. In certain conditions, the uncertainty in the number of $\mathrm{CCN}$ generated per unit mass of primary particles may exceed an order of magnitude given a factor of two uncertainty in the modal diameter of the new aerosol size distribution. In general, there is no single moment of the primary aerosol distribution (e.g. number, surface area, mass) that is a robust predictor of $\mathrm{CCN}$ formation. It appears necessary to have a more complete description of the primary aerosol size distribution to predict its impact on atmospheric CCN concentrations.

Acknowledgements. This research was supported by the United States National Aeronautics and Space Administration through grant RSP-0153-0289 and by the Environmental Protection Agency through the Science to Achieve Results (STAR) Graduate Fellowship (91668201-0). The authors would like to thank the two anonymous reviewers for their very helpful comments that have helped shape this paper.

Edited by: A. Nenes 


\section{References}

Adams, P. J. and Seinfeld, J. H.: Disproportionate impact of particulate emissions on global cloud condensation nuclei concentrations, Geophys. Res. Lett., 30, 1239, doi:10.1029/2002GL016303, 2003.

Adams, P. J. and Seinfeld, J. H.: Predicting global aerosol size distributions in general circulation models, J. Geophys. Res., 107, 4370, doi:10.1029/2001JD001010, 2002.

Albrecht, B. A.: Aerosols, Cloud Microphysics, and Fractional Cloudiness, Science, 245, 1227-1230, 1989.

Andreae, M. O., Jones, C. D., and Cox, P. M.: Strong present-day aerosol cooling implies a hot future, Nature, 435, 1187-1190, 2005.

Bond, T. C., Streets, D. G., Yarber, K. F., Nelson, S. M., Woo, J. H., and Klimont, Z.: A technology-based global inventory of black and organic carbon emissions from combustion, J. Geophys. Res.-Atmos., 109, D14203, doi:10.1029/2003JD003697, 2004.

Charlson, R. J., Schwartz, S. E., Hales, J. M., Cess, R. D., Coakley, J. A., Hansen, J. E., and Hofman, D. J.: Climate Forcing by Anthropogenic Aerosols, Science, 255, 423-430, 1992.

Clarke, A. D., Owens, S., and Zhou, J.: An ultrafine seasalt flux from breaking waves: Implications for $\mathrm{CCN}$ in the remote marine atmosphere, J. Geophys. Res., 111, D06202, doi:10.1029/2005JD006565, 2006.

Feingold, G. and Kreidenweis, S.: Does cloud processing of aerosol enhance droplet concentrations?, J. Geophys. Res.-Atmos., 105, 24 351-24 361, 2000.

Jaenicke, R.: Tropospheric Aerosols, in: Aerosol-Cloud-Climate Interactions, edited by: Hobbs, P. V., Academic Press, San Diego, 1-31, 1993.

Janhall, S., Jonsson, A. M., Molnar, P., Svensson, E. A., and Hallquist, M.: Size resolved traffic emission factors of submicrometer particles, Atmos. Environ., 38, 4331-4340, 2004.

Kerminen, V. M., Lehtinen, K. E. J., Anttila, T., and Kulmala, M.: Dynamics of atmospheric nucleation mode particles: a timescale analysis, Tellus Ser. B-Chem. Phys. Meteorol., 56, 135-146, 2004.

Menon, S.: Current uncertainties in assessing aerosol effects on climate, Ann. Rev. Environ. Resour., 29, 1-30, 2004.

Nenes, A., Pandis, S. N., and Pilinis, C.: ISORROPIA: A new thermodynamic equilibrium model for multiphase multicomponent inorganic aerosols, Aquatic Geochem., 4, 123-152, 1998.

O'Dowd, O. D., Smith, M. H., Consterdine, I. E., and Lowe, J. A.: Marine Aerosol, Sea-Salt and the Marine Sulpher Cycle: A Short Review, Atmos. Environ., 31, 73-80, 1997.

Pierce, J. R. and Adams, P. J.: Global evaluation of CCN formation by direct emission of sea salt and growth of ultrafine sea salt, J. Geophys. Res.-Atmos., 111, D06203, doi:10.1029/2005JD006186, 2006.

Poschl, U., Canagaratna, M., Jayne, J. T., Molina, L. T., Worsnop, D. R., Kolb, C. E., and Molina, M. J.: Mass accommodation coefficient of $\mathrm{H} 2 \mathrm{SO} 4$ vapor on aqueous sulfuric acid surfaces and gaseous diffusion coefficient of $\mathrm{H} 2 \mathrm{SO} 4$ in N-2/H2O, J. Phys. Chem. A, 102, 10 082-10 089, 1998.
Putaud, J. P., Raes, F., Van Dingenen, R., Bruggemann, E., Facchini, M. C., Decesari, S., Fuzzi, S., Gehrig, R., Huglin, C., Laj, P., Lorbeer, G., Maenhaut, W., Mihalopoulos, N., Mulller, K., Querol, X., Rodriguez, S., Schneider, J., Spindler, G., ten Brink, H., Torseth, K., and Wiedensohler, A.: European aerosol phenomenology-2: chemical characteristics of particulate matter at kerbside, urban, rural and background sites in Europe, Atmos. Environ., 38, 2579-2595, 2004.

Rissler, J., Vestin, A., Swietlicki, E., Fisch, G., Zhou, J., Artaxo, P., and Andreae, M. O.: Size distribution and hygroscopic properties of aerosol particles from dry-season biomass burning in Amazonia, Atmos. Chem. Phys., 6, 471-491, 2006, http://www.atmos-chem-phys.net/6/471/2006/.

Schwartz, S. E.: Uncertainty requirements in radiative forcing of climate change, J. Air Waste Manage. Assoc., 54, 1351-1359, 2004.

Seinfeld, J. H. and Pandis, S. N.: Atmospheric Chemistry and Physics, John Wiley and Sons., New York, 1998.

Sotiropoulou, R. E. P., Medina, J., and Nenes, A.: CCN predictions: Is theory sufficient for assessments of the indirect effect?, Geophys. Res. Lett., 33, L05816, doi:10.1029/2005GL025148, 2006.

Spracklen, D. V., Pringle, K. J., Carslaw, K. S., Chipperfield, M. P., and Mann, G. W.: A global off-line model of size-resolved aerosol microphysics: I. Model development and prediction of aerosol properties, Atmos. Chem. Phys., 5, 2227-2252, 2005 a.

Spracklen, D. V., Pringle, K. J., Carslaw, K. S., Chipperfield, M. P., and Mann, G. W.: A global off-line model of size-resolved aerosol microphysics: II. Identification of key uncertainties, Atmos. Chem. Phys., 5, 3233-3250, 2005 b.

Stanier, C. O., Khlystov, A. Y., and Pandis, S. N.: Ambient aerosol size distributions and number concentrations measured during the Pittsburgh Air Quality Study (PAQS), Atmos. Environ., 38, 3275-3284, 2004

Stier, P., Feichter, J., Roeckner, E., Kloster, S., and Esch, M.: Emission-induced nonlinearities in the global aerosol system, J. Climate, 19, 3845-3862, 2006.

Tang, I. N. and Munkelwitz, H. R.: Water activities, densities, and refractive indices of aqueous sulfates and sodium nitrate droplets of atmospheric importance, J. Geophys. Res., 99, 18 801-18 808, 1994.

Twomey, S.: The Influence of Pollution on the Shortwave Albedo of Clouds, J. Atmos. Sci., 34, 1149-1152, 1977.

Twomey, S.: Pollution and the Planetary Albedo, Atmos. Environ., 8, 1251-1256, 1974.

Zhang, K. M., Wexler, A. S., Niemeier, D. A., Yi, F. Z., Hinds, W. C., and Sioutas, C.: Evolution of particle number distribution near roadways. Part III: Traffic analysis and on-road size resolved particulate emission factors, Atmos. Environ., 39, 4155-4166, 2005 . 